\title{
COMBINING OPERATIONAL MODAL ANALYSIS AND GENETIC ALGORITHMS TO UNDERSTAND THE ACTUAL STRUCTURAL BEHAVIOR OF HISTORICAL CONSTRUCTIONS
}

\author{
G. Standoli ${ }^{1}$, G. P. Salachoris ${ }^{1}$, M. G. Masciotta $^{2}$ and F. Clementi ${ }^{1}$ \\ ${ }^{1}$ Dept. ICEA, Università Politecnica delle Marche, Via Brecce Bianche, 60131 Ancona, Italy \\ e-mail: \{g.standoli,g.p.salachoris\}@pm.univpm.it, francesco.clementi@univpm.it \\ ${ }^{2}$ Dept. of Engineering and Geology, University "G. d'Annunzio" of Chieti-Pescara, Viale Pindaro 42, \\ 65127 Pescara, Italy \\ e-mail: g.masciotta@unich.it
}

\begin{abstract}
Evolution of technologies both in the fields of in situ investigations and Finite Element (FE) modeling strongly enhanced the possibility to understand the structural dynamic behavior of masonry historical constructions, allowing a periodic or continuous analysis of their response to environmental, anthropic, and exceptional actions and the formulation of accurate hypotheses about their future behavior, which is fundamental for Cultural Heritage preservation. In order to improve the assessment of the health status of historical buildings, inverse methods re-sorting to dynamic identification techniques are often used to provide experimentally verified data for the accurate calibration of FE models representative of the investigated structures.

In this paper, vibration-based identification methods are coupled with an automatic FE model updating procedure to study the dynamic behavior of the Civic Tower of Ostra, Italy, and obtain baseline information for future comparative analyses. The experimental data obtained from two different campaigns of ambient vibration tests are used to update the mechanical characteristics of the detailed FE model of the tower. The updating process, unsolvable via common calibration procedures, is automatically managed through a powerful bio-inspired tool, i.e. the Genetic Algorithm (GA), allowing to closely reproduce the actual behavior of the tower.
\end{abstract}

Keywords: Masonry Towers, Cultural Heritage, Structural Health Monitoring, Operational Modal Analysis, Automated Model Updating, Genetic Algorithms. 


\section{INTRODUCTION}

Masonry towers are one of the most widespread structural typologies among the various Italian Cultural Heritage $(\mathrm{CH})$ buildings. The intrinsic characteristics and peculiarities of these artefacts make them unique objects but, at the same time, render these structures particularly vulnerable against seismic events [1-6], sometimes in irreparable way. Due to the historical, social and economic importance that $\mathrm{CH}$ plays in many countries of the world, it is crucial to guarantee appropriate maintenance plans and to undertake regular preventive actions in order to avoid irreversible damages to these iconic structures, and to historical buildings in general.

Early damage detection should be one of the primary tasks to ensure the integrity of ancient buildings and the safety of their users. To this end, several non-destructive techniques relying on the observation of the dynamic behavior of these structures, commonly known under the expression "Structural Health Monitoring (SHM)", have been developed in the last decades [7-11]. Among these techniques, those exploiting vibration-based monitoring tools can be of great help in terms of dynamic characterization of heritage towers, allowing to improve the knowledge of the global behavior of these structures without resorting to any invasive method, which is necessary when the historical value of the construction must be respected. To this end, a grid of sensors, each one communicating with a central processing unit through wires or wirelessly, can be deployed across the structure and used to collect the vibration response of the system to ambient excitations. Such data are then post-processed to determine the modal parameters of the structure in operational conditions, applying the methodologies of Operational Modal Analysis (OMA). As widely known, modal features, if tracked on a regular basis, can provide useful information for the evaluation of the health status of the structures over time, also allowing the detection of possible changes associated to their dynamic behavior in case of exceptional events [12] as well as the estimation of future structural scenarios.

With the aim of providing reliable experimental data for the calibration of realistic numerical models (NMs), closely representative of the investigated buildings, ambient vibration testing (AVT) is often coupled with another essential tool in the dynamic assessment of historical structures: the Finite Element (FE) modeling. Various examples of synergy between these two techniques can be found in the literature $[8,13,14]$, where the results obtained from OMA are employed in the process of FE model updating so that the unknown parameters of the structure (such as material properties, boundary conditions, quality of connections between elements, etc.) are iteratively updated until the difference between experimental and numerical modal results is minimized. This operation, if performed manually [15], as it often happens, can result unwieldy and onerous from a computational standpoint, making difficult to attain a precise calibration of the model in case of large and multi-dimensional problems. In order to overcome this limitation, a methodology for the automatic modal-based updating of Finite Element (FE) models is proposed hereafter making use of genetic algorithms.

The genetic algorithm (GA) is one of the oldest and most known metaheuristics used for optimization purposes [16-18]. The search for the solution space mimics, in a sense, the Darwinian theory of species evolution. In the present work, a GA provided by the open-source FE solver Code_Aster is properly exploited to automatically calibrate the elastic properties of the materials assigned to the model of the Clock Tower of Ostra, an emblematic historical tower located in Central Italy. To analyze in depth the GA potential, different mesh refinements of the tower's geometry are examined along with the adoption of an isotropic constitutive law for the materials [19-24]. 


\section{DESCRIPTION OF THE CASE STUDY: OSTRA CIVIC TOWER}

The Civic Tower of Ostra (Figure 1), also known as "Clock Tower", is the most characteristic historical structure located in the homonymous village of the Marche region, Central Italy.

Originally built in 1552 to serve as bell tower the adjacent church of San Giovanni (no longer existing today) and severely damaged during the aerial bombardments of 1944, in the second half of the XX century the Civic Tower underwent a profound intervention aimed at reinstating its sound condition. The works included the strengthening of the uncovered foundation and of the base walls as well as the restoration of some parts of the external walls and of the battlement, damaged by the bursts of artillery bullets.

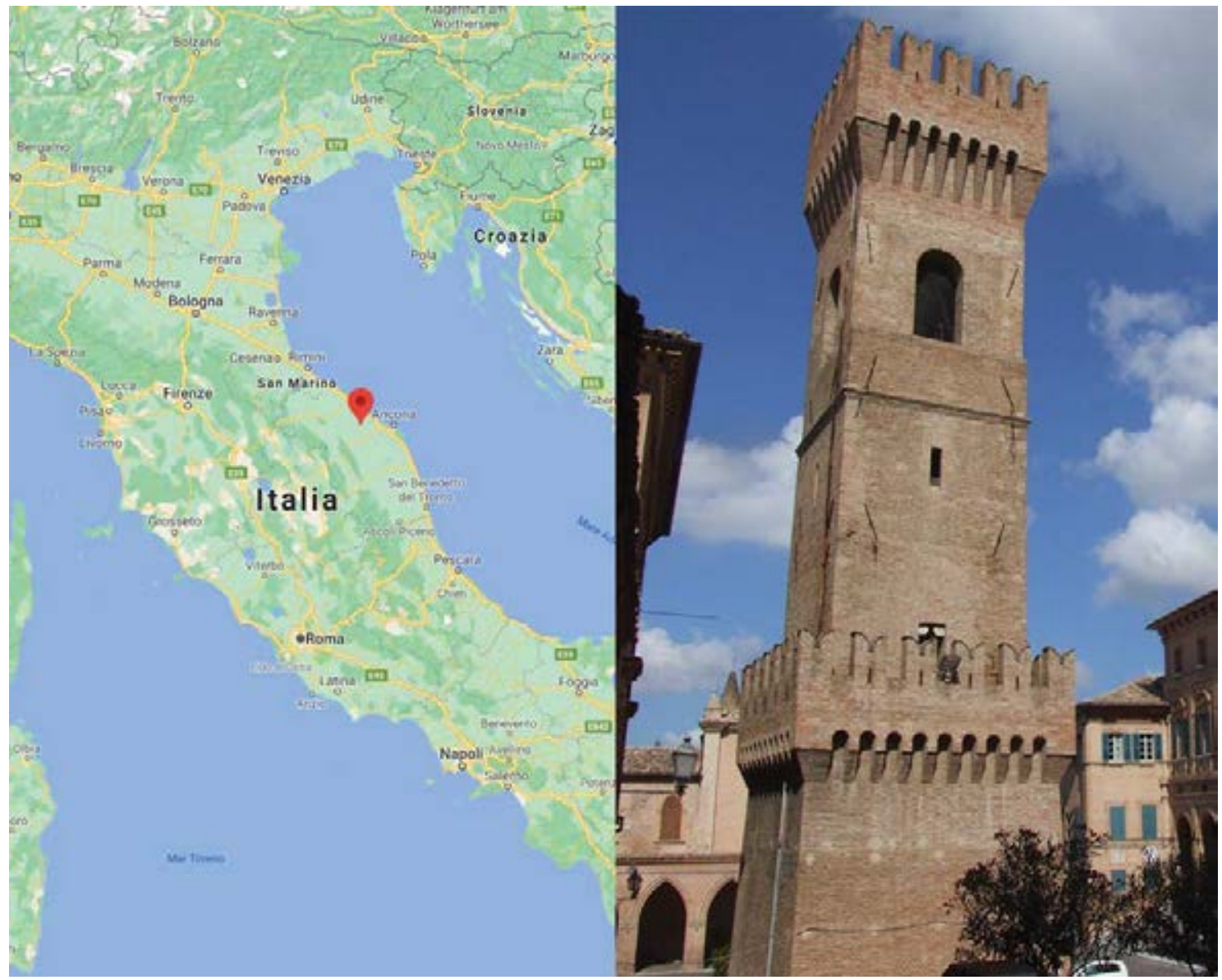

Figure 1: Ostra Civic Tower: localization and external view.

\subsection{Geometrical and material survey}

The Ostra tower is a $30 \mathrm{~m}$ high masonry structure featuring four main parts: basement, central body or shaft, belfry, and top roof (Figure 2). 

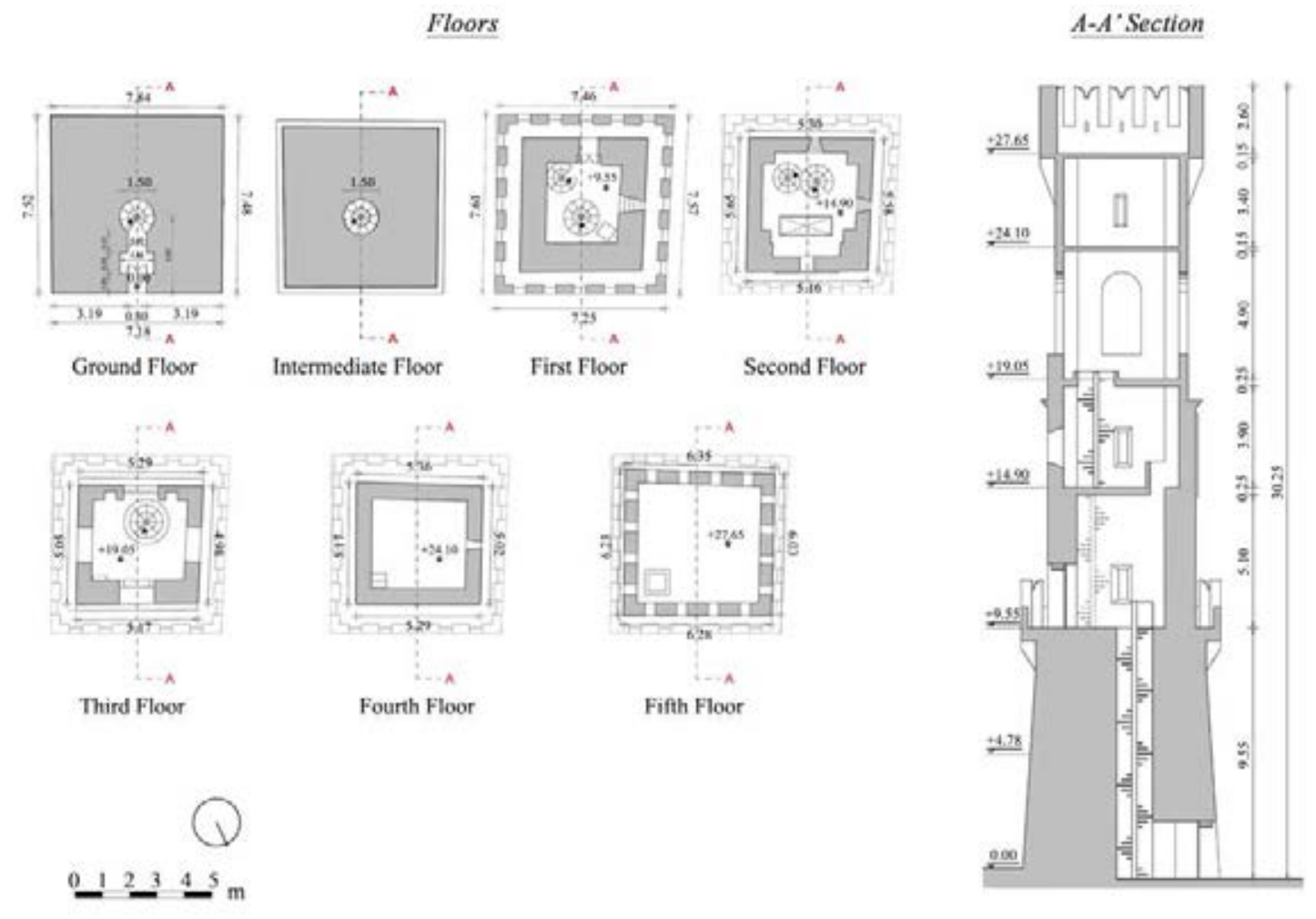

Figure 2: Geometrical survey of the investigated tower.

The basement resembles a truncated pyramid with a lower base of approximately $7.30 \mathrm{x}$ $7.50 \mathrm{~m} 2$ and an upper base of $5.30 \times 5.60 \mathrm{~m} 2$. This part is characterized by massive walls with outer brick wythes and develops upwards for a height of $9.95 \mathrm{~m}$, ending with an embattled balcony. The shaft, partially reconstructed, starts from this height and keeps the same quadrilateral cross-section for additional $9.50 \mathrm{~m}$. Then, at the level of the belfry, the tower's crosssection dimensions slightly reduce and remain unchanged till the top enlargement of the battlement. Likewise, the thickness of the brick masonry walls of both shaft and belfry progressively decreases upwards, passing from $1.1 \mathrm{~m}$ of the first floor to $0.6 \mathrm{~m}$ of the last floor.

The entrance door is located at the ground level, in correspondence of the main façade which overlooks Piazza dei Martiri. Five additional floors can be distinguished along the tower height: the first three are connected through spiral staircases, whereas the fourth (rebuilt in reinforced concrete during the intervention) and the last floor are accessible by means of an iron ladder. The clock mechanism is located on the second floor, while the bell is placed at the third level, being visible through the arch openings of the perimetral walls.

\section{AMBIENT VIBRATION TESTING}

Ambient vibration testing (AVT) has become a common technique in the world of nondestructive experimental characterization of the global behavior of historical constructions $[13,25]$ : indeed, studying the full-scale response of structures to environmental and anthropic actions in real operational conditions, namely without interrupting the normal use of the building and based on its true boundary conditions, results extremely advantageous for many rea-sons, which go far beyond the economic aspects [11]. Moreover, the non-invasive character of the experiment makes AVTs particularly suited for $\mathrm{CH}$ buildings, as proven by the numerous works that in the last years have shown the potentialities of vibration-based monitoring through accelerometric sensors in the study of the dynamic behavior of historical buildings, both in the short-term and in the long-term [26,27]. 


\subsection{Instrumentation, sensor layout and acquisition parameters}

Two AVT campaigns were conducted on the Civic Tower of Ostra to assess its dynamic behavior: the first one on 29th June 2018 and the second one on 22nd February 2019.

The sensor network which was used to acquire the structural vibration response in eight specific points defined beforehand consisted of four triaxial MEMS-based piezoelectric accelerometers (model MonoDAQ-E-gMeter) embedded into a data acquisition device simply connected to the PC by a network cable using EtherCAT protocol. One of the major advantages of this sensing system is that analog to digital conversion is performed inside the device itself, thus eliminating any noise pickup in analog cabling. Sensors were placed across four levels (Figure 4), namely at the height of $9.55 \mathrm{~m}, 14.90 \mathrm{~m}, 19.05 \mathrm{~m}$, and $27.65 \mathrm{~m}$. At each level, two MEMS accelerometers were deployed at opposite corners, thereby allowing to catch also the expected torsional modes.

To comply with the time-window length requirements [28] and in order to avoid any possible influence from non-stochastic excitations, the duration set for the signal acquisition was far greater than 2000 times the structure's fundamental period: for each setup the registration lasted around 40 minutes and the nodal processes were recorded with a sampling rate of 1024 $\mathrm{Hz}$, resulting in nearly two and a half million data points per channel.
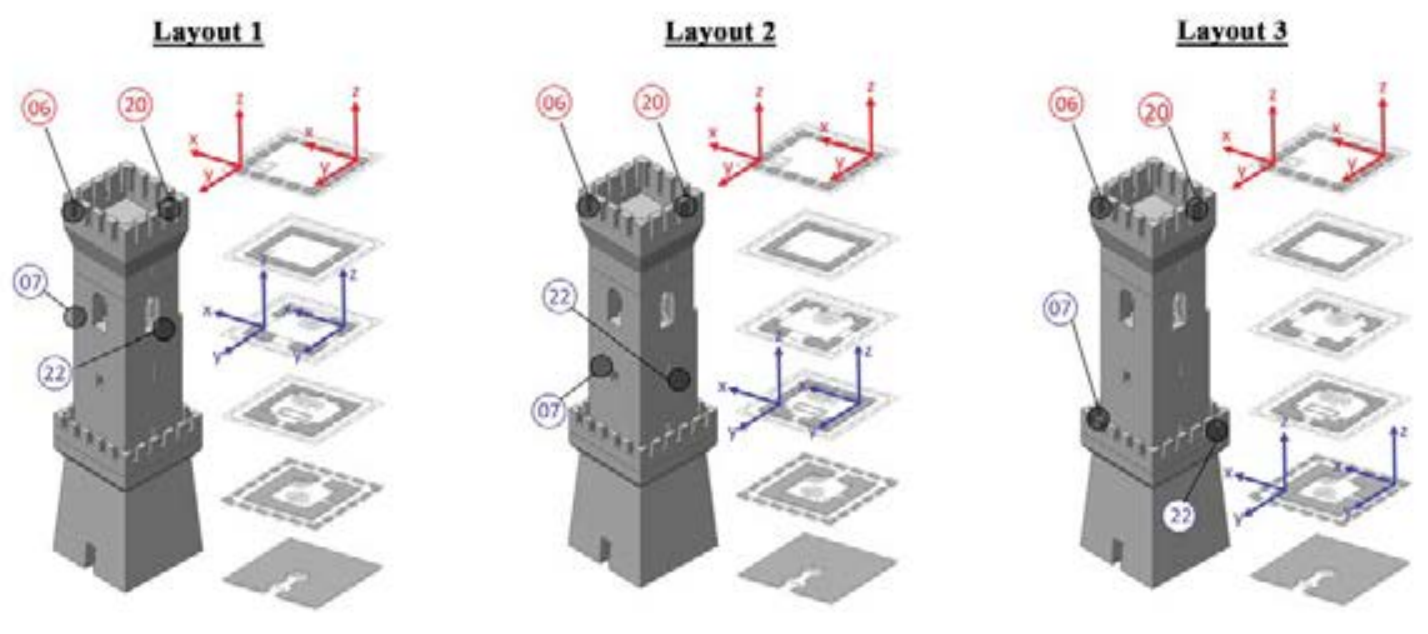

Figure 3: Sensor layouts and corresponding acceleration time series for 2018 and 2019 dynamic testing campaigns.

\subsection{Operational modal analysis: method and results}

The elaboration of the acquired vibration data allowed the construction of an Experimental Model (EM) of the structure, whose estimated dynamic parameters were subsequently employed to calibrate the Numerical Model (NM) of the tower in order to realistically reproduce its structural behavior, as better discussed in the next Section. The dynamic feature extraction process was carried out and cross-validated through the application of two OMA techniques: the Enhanced Frequency Domain Decomposition (EFDD) [29] and the Stochastic Subspace Identification - Principal Components (SSI-PC) [30], both available in the commercial software ARTeMIS [31].

Modal frequencies (f), damping ratios $(\xi)$ and mode shapes of the five vibration modes identified in each AVT campaign are reported and compared in Table 1 and Figure 4, respectively. 


\begin{tabular}{llllllll}
\hline \multirow{2}{*}{ Mode } & $\begin{array}{l}f_{\text {EM18 }} \\
{[\mathrm{Hz}]}\end{array}$ & $\xi_{\text {EM18 }}[\%]$ & $\begin{array}{l}f_{\text {EM19 }} \\
{[\mathrm{Hz}]}\end{array}$ & $\xi_{\text {EM19 }}[\%]$ & $\Delta f[\%]$ & $\Delta \xi[\%]$ & $\begin{array}{l}\text { MAC } \\
{[\%]}\end{array}$ \\
\hline$\varphi 1$ & 2.082 & 0.817 & 2.092 & 0.762 & 0.478 & -7.218 & 99.2 \\
$\varphi 2$ & 2.156 & 0.893 & 2.165 & 0.787 & 0.416 & -13.469 & 99.5 \\
$\varphi 3$ & 6.293 & 0.578 & 6.302 & 0.666 & 0.143 & 13.213 & 98.1 \\
$\varphi 4$ & 6.442 & 2.423 & 6.449 & 3.397 & 0.109 & 28.672 & 99.0 \\
$\varphi 5$ & 6.941 & 2.463 & 6.872 & 2.739 & -1.004 & 10.077 & 97.1 \\
\hline
\end{tabular}

Table 1: Modal frequencies and damping ratios estimated for EM2018 and EM2019 along with their corresponding percentage variation.

As expected, the first two identified frequency values correspond to the translational modes of the tower in $\mathrm{x}$ and $\mathrm{y}$ directions, respectively, thus resulting quite closely spaced (with a difference of just $3.43 \%$ in 2018 and $3.37 \%$ in 2019). The other three frequency values fall in the range 6-7 Hz and correspond to the torsion and double bending modes of the tower. The frequency results, sensibly higher if compared to commonly studied masonry towers, are not only affected by the low aspect ratio of the structure $(\lambda=4)$ but also highlight an elevated stiffness of the system which is likely imputable to past restoring interventions. No substantial variation in the dynamic behavior of the structure is recorded during the period elapsed between the dynamic campaigns. 
a)

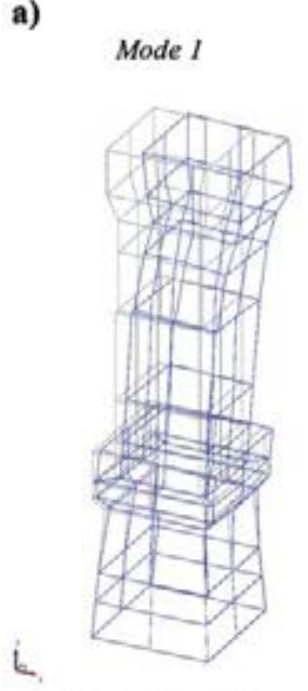

Translational $X$ k

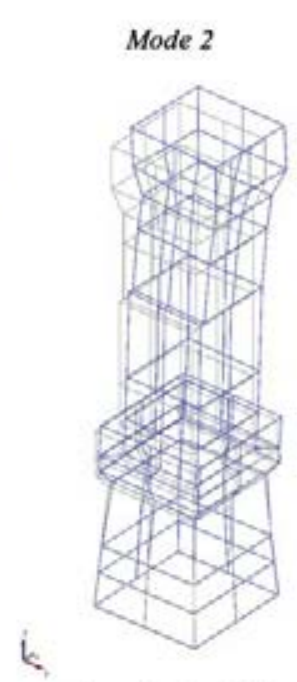

Translational $Y$ i.

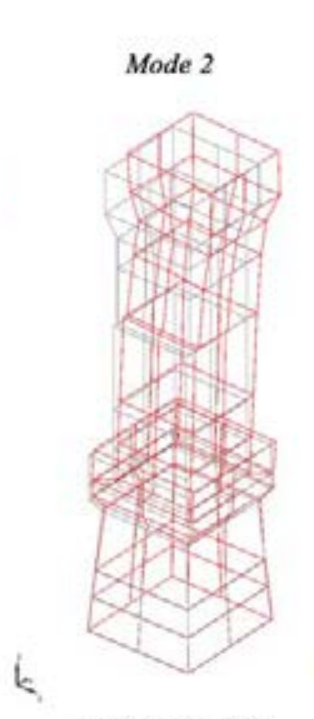

\section{8}

Mode 3

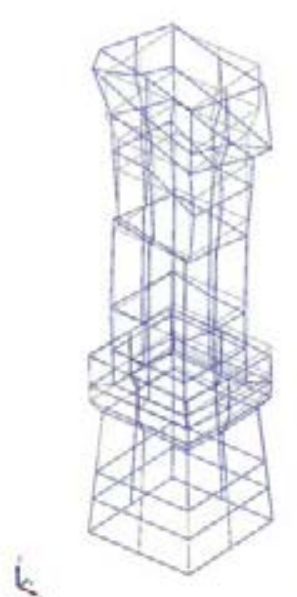

Torsional

2019

Mode 3

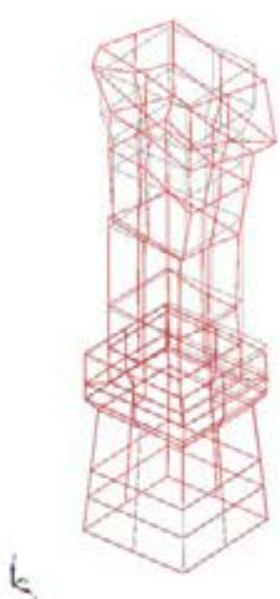

Torsional

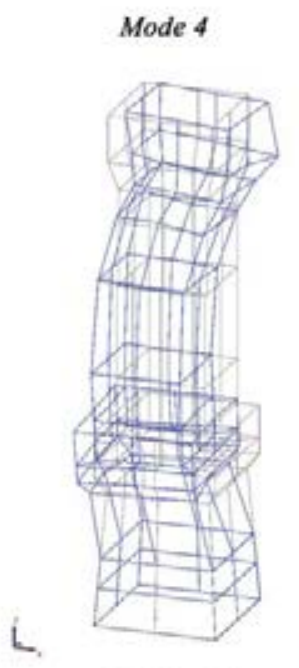

Bending $X$

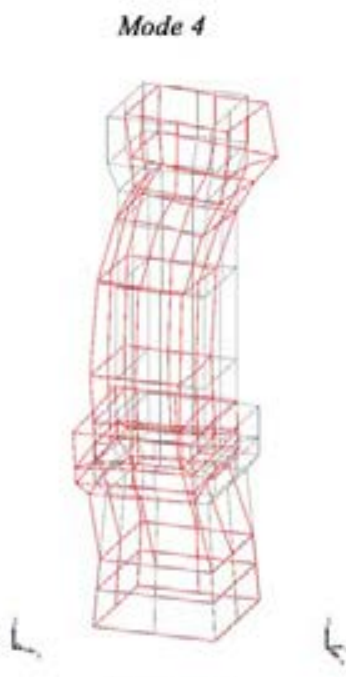

Bending $X$

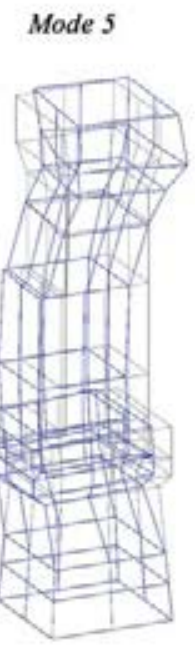

Bending $Y$

Mode 5

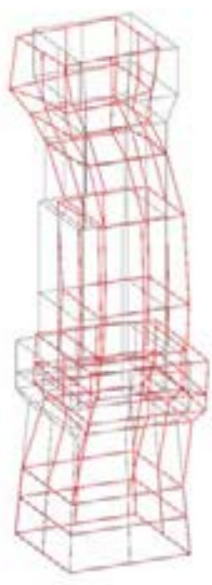

Bending $Y$

Figure 4: Comparison between the mode shapes of EM 2018 (a) and the corresponding ones of EM 2019 (b).

\section{AUTOMATIC MODEL UPDATING WITH GENETIC ALGORITHM}

\subsection{Preliminary FE model and modal analysis results}

A FE model of the tower was realized using MidasFea(C. This NM was needed in the first stage to preliminary assess the dynamic characteristics of the tower and drive the setting of the acquisition parameters for the field-testing campaign.

Particular attention was paid to the geometrical features of the tower as well as to the modeling of the masonry infill walls present in the first two levels, given the nonnegligible influence of both aspects in the modal response of the structure. The reinforced concrete floors were considered as rigid in their plane, while secondary elements, like stairs, deformable wooden floors, clock mechanism and towers, were not explicitly modelled, but their presence was taken into account in the form of added masses. 
a)

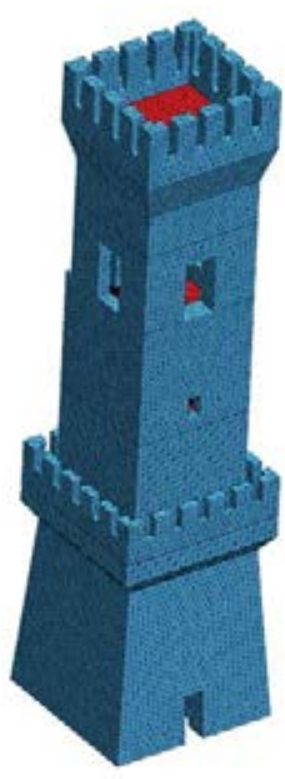

b)

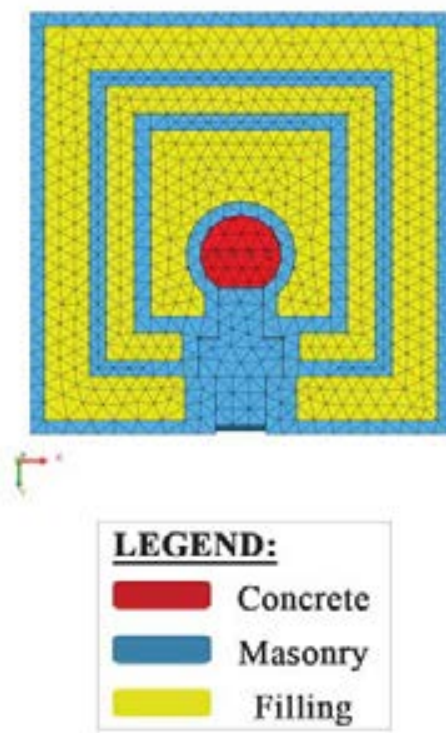

Figure 5: FE modeling of the Civic Tower of Ostra: (a) Assonometric view, (b) Bottom view at foundation level.

The FE model, shown in Figure 5, consisted of 78926 4-nodes tetrahedral elements and 21726 nodes. The mesh size was established equal to $0.3 \mathrm{~m}$. The tower was assumed to be clamped at the base and constituted by three groups of homogeneous and isotropic materials (three-group discretization) whose initial mechanical properties, chosen in accordance to the Italian Technical Standards for Structures [32], are reported in Table 2.

\begin{tabular}{llcl}
\hline Material & $E[\mathrm{MPa}]$ & $\mathrm{v}[-]$ & $\gamma\left[\mathrm{kN} / \mathrm{m}^{3}\right]$ \\
\hline Masonry & 1800 & 0.20 & 18 \\
Concrete & 18000 & 0.20 & 25 \\
Filling & 1100 & 0.20 & 18 \\
\hline
\end{tabular}

Table 2: Mechanical properties of the initial FE model: Young's Modulus (E), Poisson's ratio (v) and mass density $(\gamma)$.

The results of the preliminary modal analysis, implemented through the Lanczos method $[17,21,33,34]$, are resumed in Table 3 and Figure 6. A remarkable difference is found among the frequencies of the EM and those of the NM, being the latter not yet calibrated on the basis of the experimental outcome.

\begin{tabular}{llllllllll}
\hline & & Eff. & Eff. & & & & & \\
Mode & $f_{\mathrm{NM} 0}$ & Mass & Mass & $f_{\mathrm{EM} 18}$ & $f_{\text {EM19 }}$ & $\left|\Delta f_{\mathrm{EM} 18-\mathrm{NM} 0}\right|$ & $\begin{array}{l}\text { MAC } \\
\text { NM0 } 18-\end{array}$ & $\left|\Delta f_{\mathrm{EM} 19-\mathrm{NM} 0}\right|$ & $\begin{array}{l}\text { MAC } \\
\text { NM0 }\end{array}$ \\
& {$[\mathrm{Hz}]$} & $\begin{array}{l}\mathrm{X} \text { dir } \\
{[\%]}\end{array}$ & $\begin{array}{l}\text { Y dir } \\
{[\mathrm{Hz}]}\end{array}$ & {$[\mathrm{Hz}]$} & {$[\%]$} & {$[\%]$} & & {$[\%]$} \\
\hline$\varphi 1$ & 1.509 & 35.80 & 0.00 & 2.082 & 2.092 & 27.52 & 77.6 & 27.87 & 82.5 \\
$\varphi 2$ & 1.536 & 0.00 & 35.72 & 2.156 & 2.165 & 28.76 & 81.5 & 29.05 & 67.2 \\
$\varphi 3$ & 5.012 & 0.00 & 0.00 & 6.293 & 6.302 & 20.36 & 22.1 & 20.47 & 2.6
\end{tabular}




\begin{tabular}{llllllllll}
$\varphi 4$ & 5.821 & 21.21 & 0.00 & 6.442 & 6.449 & 9.64 & 52.2 & 9.74 & 47.6 \\
$\varphi 5$ & 5.883 & 0.00 & 29.38 & 6.941 & 6.872 & 15.24 & 1.1 & 14.39 & 44.7 \\
\hline
\end{tabular}

Table 3: Preliminary numerical results (NM0) and percentage error with the experimental frequencies (EM)

Analogous considerations can be drawn about the mode shapes (Figure 6), whose main displacement components are visually correlated with their experimental counterpart - being the first two modes translational in $\mathrm{x}$ and $\mathrm{y}$ direction, the third torsional, and the last two double bending modes in $\mathrm{x}$ and $\mathrm{y}$ direction - but a low degree of consistency is found between them when MAC values are computed (Table 3).

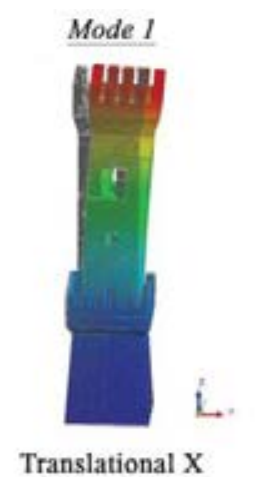

Translational X

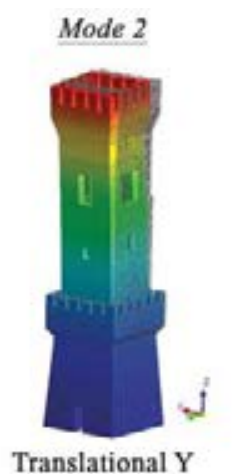

Figure 6: Mode shapes of the preliminary FE model.
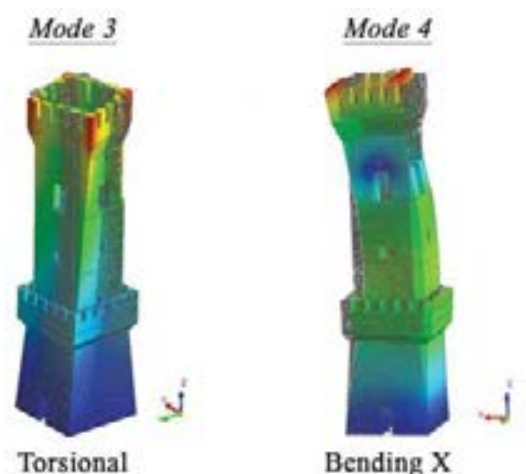

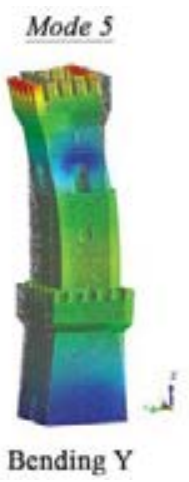

\subsection{Genetic Algorithms}

The genetic algorithms (GAs) are heuristic techniques inspired by Darwin's theory and are based on the imitation of the natural selection process. These algorithms allow to solve optimization problems through an automatic procedure where the final set of optimal solutions is iteratively selected from an initial set of candidate solutions, based on their fitness score [3538]. As for the present case, the initial population of solutions was represented by all the plausible values of material properties falling within pre-defined upper and lower bounds $[17,18]$. A two-term objective function considering both frequencies and mode shapes residuals between EM and NM was employed for the selection of the optimal values.

In order to avoid the limitations imposed by a manual calibration approach, the iterative process was implemented into Code_Aster(C) software environment. The procedure, summarized in Figure 7, started with the creation of a condensed model, carrying all the dynamic characteristics of the EM, and with its projection onto the NM. This operation allows scaling the EM DOFs up to those of the NM and, consequently, the creation of dependencies for calculating the gaps between their nodal displacements. 


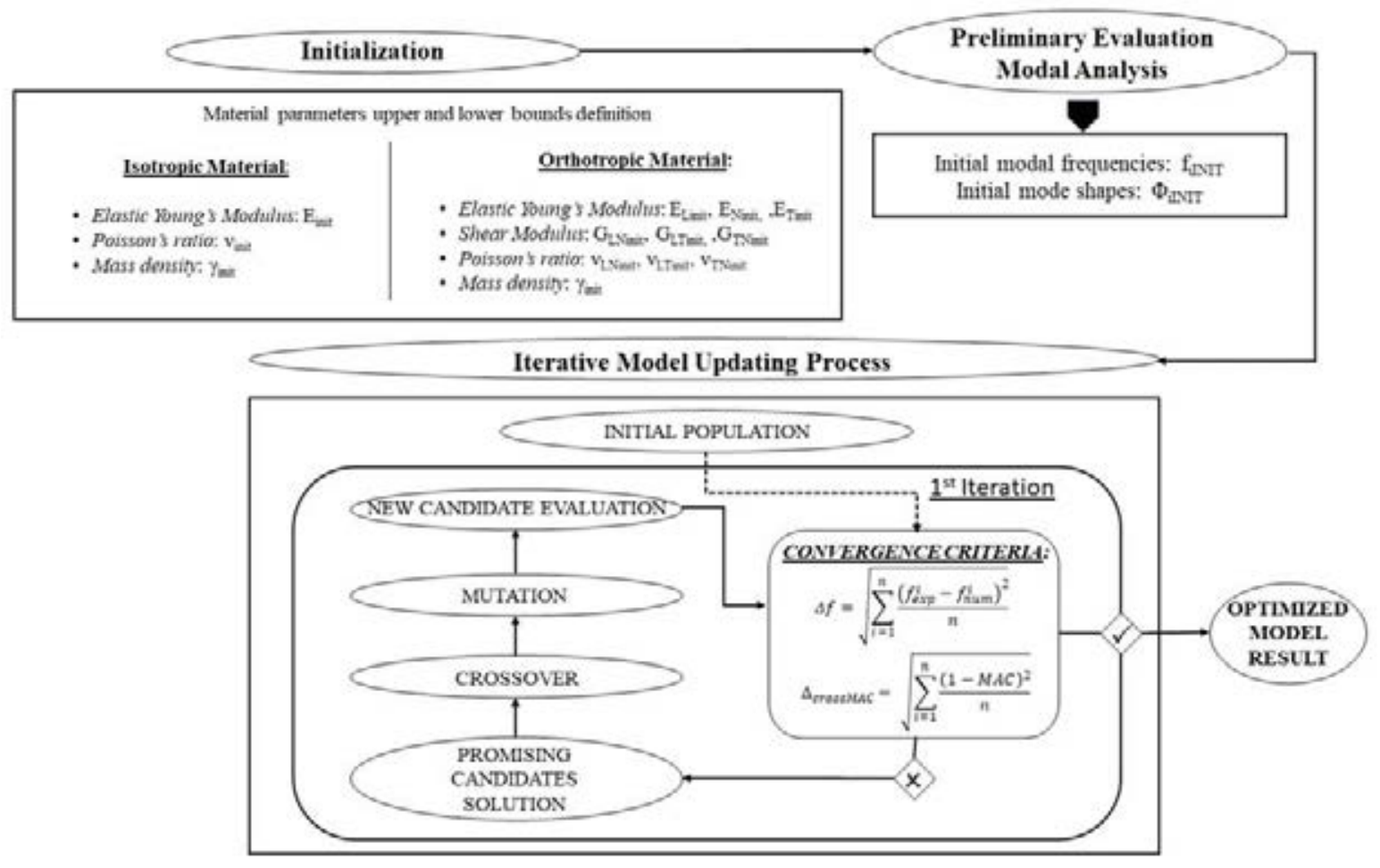

Figure 7: GA-based model updating flowchart.

The model updating process consisted of four phases (objective function, selection, crossover, mutation) and stopped only when the global optimum was located. Indeed, one of the main advantages of GA is the possibility to explore diverse regions of interest by running the same search problem on different conditions and finally locate the global optimum without getting trapped in local minima $[16,17,39,40]$. In the present work, these conditions are checked by resorting to the following objective function (1):

$$
\begin{aligned}
& \Delta f=\sqrt{\sum_{i=1}^{n} \frac{\left(f_{\exp }^{i}-f_{\text {num }}^{i}\right)^{2}}{n}} \\
& \Delta_{\text {cross } M A C}=\sqrt{\sum_{i=1}^{n} \frac{(1-M A C)^{2}}{n}}
\end{aligned}
$$

Convergence criteria were satisfied when the residual tolerance of two consecutive steps reached $1 \mathrm{e}-4$ or after 1000 evaluations.

\section{CALIBRATION PROCESS AND RESULTS}

In order to improve control over the model dynamic response and to achieve a better tuning with the experimental data, the calibration process was performed operating a further discretization of the preliminary NM in terms of material properties distribution, while the mesh size remained unchanged. This operation was driven by the careful observation of the masonry appearance and morphology across the tower, which ultimately led to a twelve-group discretization of the updating variables (Figure 8). 


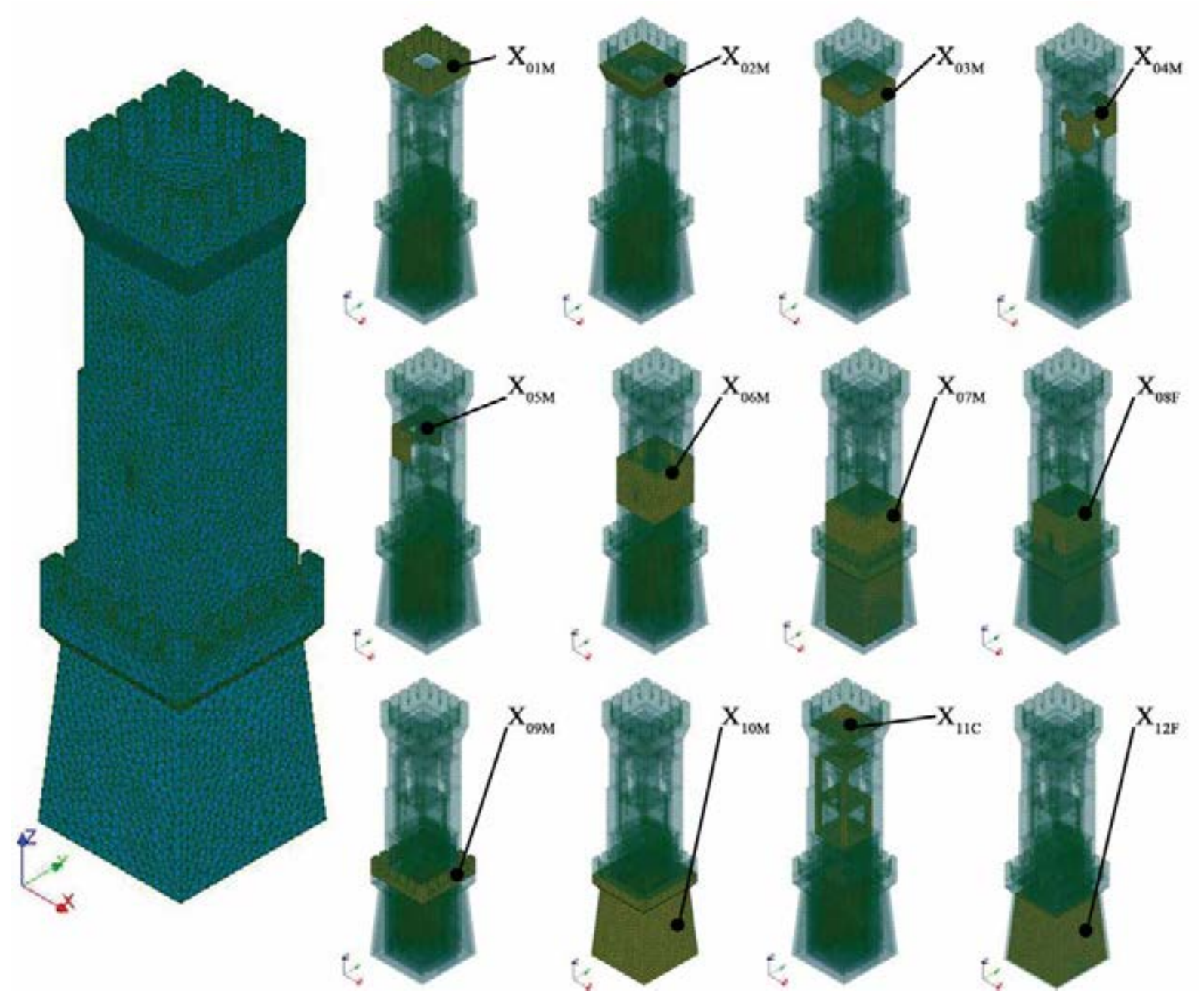

Figure 8: Updating variables for the twelve-group discretization of the FE model. Each material group is named as "X" followed by a subscript composed by a number (00 to 12), which stands for the group, and a letter indicating the material ("M": masonry, "C": concrete, "F": masonry infill).

For each group, properties were attributed considering an isotropic constitutive law for the materials, thus leading to a total number of 36 updating variables. The pre-defined ranges of variability for the material parameters, presented in Table 4, were again assigned in accordance with the Italian Technical Standards for Structures [32].

\begin{tabular}{llcl}
\hline \multirow{2}{*}{ Material } & $\begin{array}{l}E[\mathrm{MPa}] \\
\text { Min - Max }\end{array}$ & $\begin{array}{c}\mathrm{V}[-] \\
\text { Min - Max }\end{array}$ & $\begin{array}{l}\gamma\left[\mathrm{kN} / \mathrm{m}^{3}\right] \\
\text { Min - Max }\end{array}$ \\
\hline Masonry & $600-3300$ & $0.01-0.45$ & $15-20$ \\
Filling & $600-2400$ & $0.01-0.45$ & $15-20$ \\
Concrete & $27000-32000$ & $0.01-0.45$ & $23-26$ \\
\hline
\end{tabular}

Table 4: Lower and upper bounds for isotropic elastic properties

The optimal mechanical properties resulting from the model updating are summarized in Table 5. It is worth noting that the obtained values, especially the Young's Moduli, consistent-ly reflect the masonry changes produced by the strengthening interventions that the 
Tower underwent in the past: indeed, E first tends to decrease moving from the basement (restored during the 1950s) to the central body (partially restored) and the belfry, and then increases towards the top part of the tower (added afterwards).

\begin{tabular}{lllllll}
\hline & NM 2018 & \multicolumn{5}{c}{ NM 2019 } \\
\hline $\begin{array}{l}\text { Updating } \\
\text { Parameter }\end{array}$ & $E[\mathrm{MPa}]$ & $\mathrm{v}[-]$ & $\gamma\left[\mathrm{kN} / \mathrm{m}^{3}\right]$ & $E[\mathrm{MPa}]$ & $\mathrm{v}[-]$ & $\gamma\left[\mathrm{kN} / \mathrm{m}^{3}\right]$ \\
\hline $\mathrm{X}_{01 \mathrm{M}}$ & 1909 & 0.11 & 15 & 1616 & 0.28 & 15 \\
$\mathrm{X}_{02 \mathrm{M}}$ & 2783 & 0.10 & 15 & 1886 & 0.15 & 15 \\
$\mathrm{X}_{03 \mathrm{M}}$ & 851 & 0.16 & 15 & 618 & 0.21 & 15 \\
$\mathrm{X}_{04 \mathrm{M}}$ & 1118 & 0.18 & 16 & 1500 & 0.14 & 18 \\
$\mathrm{X}_{05 \mathrm{M}}$ & 1202 & 0.15 & 15 & 1417 & 0.22 & 15 \\
$\mathrm{X}_{06 \mathrm{M}}$ & 3152 & 0.17 & 18 & 3194 & 0.18 & 18 \\
$\mathrm{X}_{07 \mathrm{M}}$ & 3113 & 0.21 & 20 & 3154 & 0.16 & 20 \\
$\mathrm{X}_{08 \mathrm{~F}}$ & 2368 & 0.16 & 20 & 2344 & 0.14 & 20 \\
$\mathrm{X}_{09 \mathrm{M}}$ & 2623 & 0.17 & 18 & 2491 & 0.17 & 18 \\
$\mathrm{X}_{10 \mathrm{M}}$ & 3290 & 0.23 & 20 & 2724 & 0.27 & 19 \\
$\mathrm{X}_{11 \mathrm{C}}$ & 27096 & 0.15 & 24 & 28833 & 0.33 & 24 \\
$\mathrm{X}_{12 \mathrm{~F}}$ & 1662 & 0.19 & 17 & 1951 & 0.27 & 20 \\
\hline
\end{tabular}

Table 5: Optimal values for the material parameters of the isotropic FE model after calibration

The results of the modal analyses run over 2018 and 2019 NMs, both calibrated through the automatic GA-based procedure previously described, are exposed in Table 6 and Table 7. The comparison between EM and NM frequency values is satisfactory, being the relative error less than $3 \%$ in all cases, with the sole exception of the 4th mode that shows a slightly higher error for the pair EM18-NM18.

\begin{tabular}{lllllll}
\hline & & & Eff. & Eff. \\
Mode & $f_{\text {EM18 }}$ & $f_{\text {NM18 }}$ & $\begin{array}{l}\text { Mass } \\
\text { X dir } \\
{[\mathrm{Hz}]}\end{array}$ & $\begin{array}{l}\text { Mass } \\
\text { Y dir } \\
{[\%]}\end{array}$ & $\begin{array}{l}\left|\Delta f_{\text {EM18-NM18 }}\right| \\
{[\%]}\end{array}$ & $\begin{array}{l}\text { MACEM18- } \\
\text { NM18 } \\
{[\%]}\end{array}$ \\
\hline$\varphi 1$ & 2.082 & 2.087 & 34.14 & 0.01 & 0.24 & 97.9 \\
$\varphi 2$ & 2.156 & 2.130 & 0.01 & 33.53 & 1.21 & 97.3 \\
$\varphi 3$ & 6.293 & 6.274 & 0.26 & 0.00 & 0.30 & 97.2 \\
$\varphi 4$ & 6.442 & 6.654 & 29.89 & 0.11 & 3.29 & 95.7 \\
$\varphi 5$ & 6.941 & 6.799 & 0.12 & 29.25 & 2.05 & 95.3 \\
\hline
\end{tabular}

Table 6: Comparison between 2018 experimental (EM) and numerical (NM) frequencies

\begin{tabular}{|c|c|c|c|c|c|c|}
\hline Mode & $\begin{array}{l}\mathrm{f}_{\mathrm{EM} 19} \\
{[\mathrm{~Hz}]}\end{array}$ & $\begin{array}{l}\mathrm{f}_{\mathrm{NM} 19} \\
{[\mathrm{~Hz}]}\end{array}$ & $\begin{array}{l}\text { Eff. } \\
\text { Mass } \\
\text { Direc- } \\
\text { tion X } \\
{[\%]}\end{array}$ & $\begin{array}{l}\text { Eff. } \\
\text { Mass } \\
\text { Direc- } \\
\text { tion Y } \\
{[\%]}\end{array}$ & $\begin{array}{l}\left|\Delta f_{\text {EM19-NM19 }}\right| \\
{[\%]}\end{array}$ & $\begin{array}{l}\text { MACEM19- } \\
\text { NM19 } \\
{[\%]}\end{array}$ \\
\hline$\varphi 1$ & 2.092 & 2.097 & 33.94 & 0.00 & 0.24 & 96.5 \\
\hline$\varphi 2$ & 2.165 & 2.141 & 0.00 & 33.41 & 1.11 & 96.6 \\
\hline$\varphi 3$ & 6.302 & 6.275 & 0.41 & 0.06 & 0.43 & 95.7 \\
\hline
\end{tabular}




\begin{tabular}{lllllll}
$\varphi 4$ & 6.449 & 6.629 & 29.22 & 0.03 & 2.79 & 95.8 \\
$\varphi 5$ & 6.872 & 6.761 & 0.02 & 28.48 & 1.62 & 95.8 \\
\hline
\end{tabular}

Table 7: Comparison between 2019 experimental (EM) and numerical (NM) frequencies

a)

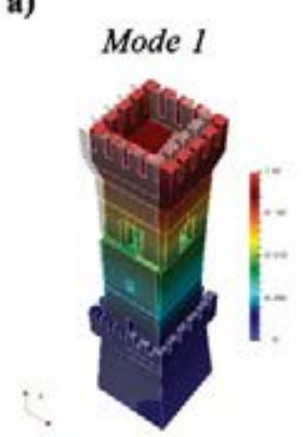

Translational $X$

b)

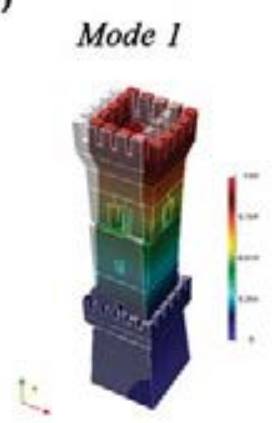

Translational $X$

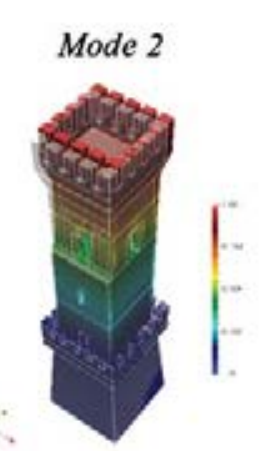

Translational $Y$

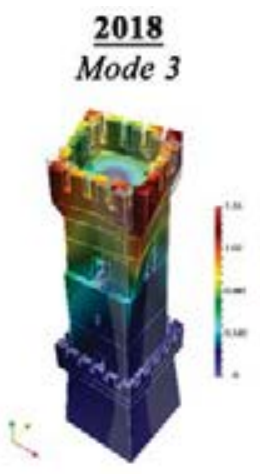

Torsional

2019

Mode 3

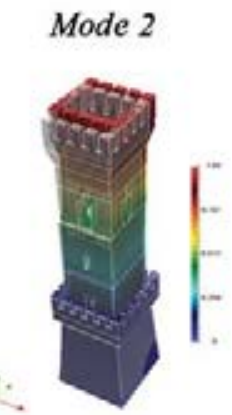

Translational $Y$

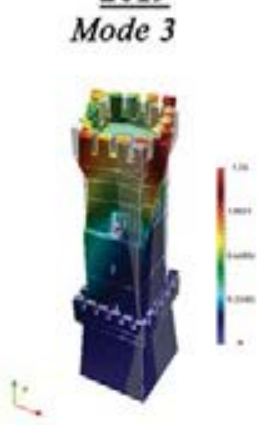

Torsional

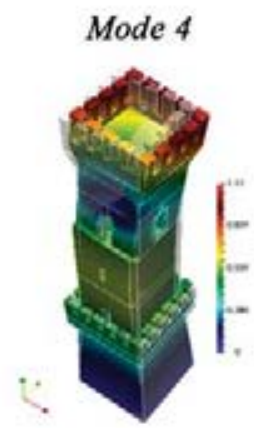

Bending $X$

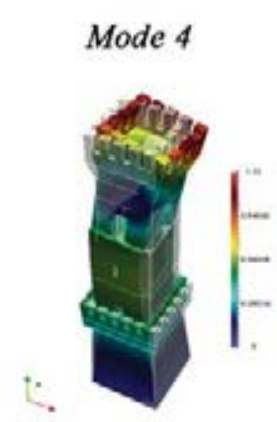

Bending $X$

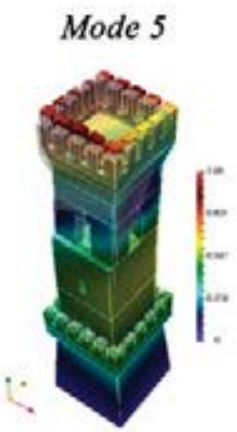

Bending $Y$

Mode 5

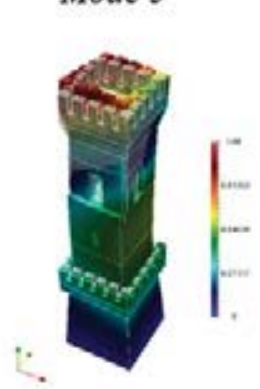

Bending $Y$

Figure 9: Numerical mode shapes after calibration of 2018 NM and 2019 NM.

Very good results are also achieved in terms of mode shapes (Figure 9), as confirmed by the optimal levels of correlation (MAC $>95 \%$ ) obtained from the comparison between experimental and calibrated modal vectors, proving the validity and robustness of the GA-based model updating when tackling optimization problems otherwise ungovernable with conventional approaches.

\section{CONCLUSIONS}

The paper showed and discussed the results obtained by combining AVT-based dynamic identification methodologies and FE model updating techniques, through the application of an automatic procedure based on GA for the assessment of the dynamic behavior of the Ostra Civic Tower (Italy).

After an initial geometrical and material survey to define the main morphological and structural characteristics necessary for the creation of a preliminary NM (over which more advanced non-linear analyses will be implemented in order to estimate the structural response against future scenarios), two modal testing campaigns were carried out to acquire the vibration response of the tower to ambient noise. Innovative sensing solutions based on MEMS were adopted for this purpose. 
After extracting the main dynamic parameters of the tower (i.e. modal frequencies, modal damping and mode shapes) through well-known OMA techniques, the EM of the structure was implemented into Code_AsterC and used as a target reference for the calibration of the afore-mentioned finite element NM. In both campaigns, the same five vibration modes were identified, meaning that no changes in the structural condition of the tower occurred between 2018 and 2019.

All the eigenfrequencies and eigenvectors associated to these five modes were exploited for the subsequent automated calibration process, which consisted in a perturbation of the mass and stiffness matrices of the NM in order to find optimal yet physically meaningful values of the unknown material properties of the tower, so that the difference between estimated (OMA) and calculated (FEM) eigen-parameters was minimized. The search problem was solved by applying a metaheuristic inspired by the process of natural selection, namely the GA, to the OMA eigen-data projected onto the equivalent NM. The employment of such an algo-rithm was pivotal given the population of candidate solutions taken into account for the mod-al-based FE updating.

The results, obtained assuming an isotropic behavior for the materials, were satisfactory. Future developments will take into consideration orthotropic constitutive laws for the masonry in the attempt to further minimize the discrepancies between numerical and experimental models.

\section{REFERENCES}

[1] M. Acito, M. Bocciarelli, C. Chesi, G. Milani, Collapse of the clock tower in Finale Emilia after the May 2012 Emilia Romagna earthquake sequence: Numerical insight, Eng. Struct. 72 (2014) 70-91. https://doi.org/10.1016/j.engstruct.2014.04.026.

[2] M. Betti, A. Vignoli, Numerical assessment of the static and seismic behaviour of the basilica of Santa Maria all'Impruneta (Italy), Constr. Build. Mater. 25 (2011) 43084324. https://doi.org/10.1016/j.conbuildmat.2010.12.028.

[3] G. Brandonisio, G. Lucibello, E. Mele, A. De Luca, Damage and performance evaluation of masonry churches in the 2009 L'Aquila earthquake, Eng. Fail. Anal. 34 (2013) 693-714. https://doi.org/10.1016/j.engfailanal.2013.01.021.

[4] G. Milani, Lesson learned after the Emilia-Romagna, Italy, 20-29 May 2012 earthquakes: A limit analysis insight on three masonry churches, Eng. Fail. Anal. 34 (2013) 761-778. https://doi.org/10.1016/j.engfailanal.2013.01.001.

[5] S. Lagomarsino, S. Podestà, Damage and Vulnerability Assessment of Churches after the 2002 Molise, Italy, Earthquake, Earthq. Spectra. 20 (2004) 271-283. https://doi.org/10.1193/1.1767161.

[6] A. Ferrante, F. Clementi, G. Milani, Dynamic Behavior of an Inclined Existing Masonry Tower in Italy, Front. Built Environ. 5 (2019). https://doi.org/10.3389/fbuil.2019.00033.

[7] F. Magalhães, A. Cunha, E. Caetano, Vibration based structural health monitoring of an arch bridge: From automated OMA to damage detection, Mech. Syst. Signal Process. 28 (2012) 212-228. https://doi.org/10.1016/j.ymssp.2011.06.011.

[8] M. Pieraccini, D. Dei, M. Betti, G. Bartoli, G. Tucci, N. Guardini, Dynamic identification of historic masonry towers through an expeditious and no-contact approach: Appli- 
cation to the "Torre del Mangia" in Siena (Italy), J. Cult. Herit. 15 (2014) 275-282. https://doi.org/10.1016/j.culher.2013.07.006.

[9] N. Cavalagli, G. Comanducci, C. Gentile, M. Guidobaldi, A. Saisi, F. Ubertini, Detecting earthquake-induced damage in historic masonry towers using continuously monitored dynamic response-only data, Procedia Eng. 199 (2017) 3416-3421. https://doi.org/10.1016/j.proeng.2017.09.581.

[10] A. Saisi, C. Gentile, A. Ruccolo, Static and dynamic monitoring of a Cultural Heritage bell-tower in Monza, Italy, Procedia Eng. 199 (2017) 3356-3361. https://doi.org/10.1016/j.proeng.2017.09.563.

[11] M.G. Masciotta, L.F. Ramos, Dynamic identification of historic masonry structures, in: P.B. Ghiassi, Bahman; Lourenco (Ed.), Long-Term Perform. Durab. Mason. Struct., Woodhead, Publishing Series in Civil and Structural Engineering, Woodhead Publishing (2019), 2019: pp. 241-264. https://doi.org/10.1016/B978-0-08-102110-1.00008-X.

[12] P.F. Giordano, F. Ubertini, N. Cavalagli, A. Kita, M.G. Masciotta, Four years of structural health monitoring of the San Pietro bell tower in Perugia, Italy: two years before the earthquake versus two years after, Int. J. Mason. Res. Innov. 5 (2020) 445-467. https://doi.org/10.1504/IJMRI.2020.111797.

[13] F. Clementi, A. Pierdicca, A. Formisano, F. Catinari, S. Lenci, Numerical model upgrading of a historical masonry building damaged during the 2016 Italian earthquakes: the case study of the Podestà palace in Montelupone (Italy), J. Civ. Struct. Heal. Monit. 7 (2017) 703-717. https://doi.org/10.1007/s13349-017-0253-4.

[14] C. Gentile, A. Saisi, P. Borlenghi, FE modelling for seismic assessment of an ancient tower from ambient vibration survey, in: 8th IOMAC - Int. Oper. Modal Anal. Conf., Copenhagen, 2019: pp. 295-305. http://hdl.handle.net/11311/1124063.

[15] G. Standoli, E. Giordano, G. Milani, F. Clementi, Model Updating of Historical Belfries Based on Oma Identification Techniques, Int. J. Archit. Herit. (2020) 1-25. https://doi.org/10.1080/15583058.2020.1723735.

[16] T. Bartz-Beielstein, J. Branke, J. Mehnen, O. Mersmann, Evolutionary Algorithms, Wiley Interdiscip. Rev. Data Min. Knowl. Discov. 4 (2014) 178-195. https://doi.org/10.1002/widm.1124.

[17] M. Girardi, C. Padovani, D. Pellegrini, L. Robol, A finite element model updating method based on global optimization, Mech. Syst. Signal Process. (2020) 107372. https://doi.org/10.1016/j.ymssp.2020.107372.

[18] D. Pellegrini, M. Girardi, P.B. Lourenço, M.G. Masciotta, N. Mendes, C. Padovani, L.F. Ramos, Modal analysis of historical masonry structures: Linear perturbation and software benchmarking, Constr. Build. Mater. 189 (2018) 1232-1250. https://doi.org/10.1016/j.conbuildmat.2018.09.034.

[19] M.. Betti, G.. Bartoli, R.. Corazzi, V.. Kovacevic, Strumenti Open Source per l'ingegneria strutturale. Modellazione meccanica non lineare di edifici in muratura, Boll. Ing. 60 (2013) 3-15.

[20] G. Bartoli, M. Betti, A.M. Marra, S. Monchetti, A Bayesian model updating framework for robust seismic fragility analysis of non-isolated historic masonry towers, Philos. Trans. R. Soc. A Math. Phys. Eng. Sci. $377 \quad$ (2019) 20190024. https://doi.org/10.1098/rsta.2019.0024. 
[21] A. Garcia-Gonzalez, A. Gonzalez-Herrera, A. Garcia-Cerezo, Damage Localization based on Modal Parameters using the Finite Element Method and Neural Networks, in: n.d. https://doi.org/10.4203/ccp.93.48.

[22] K. Smarsly, K. Dragos, J. Wiggenbrock, Machine learning techniques for structural health monitoring, 8th Eur. Work. Struct. Heal. Monit. EWSHM 2016. 2 (2016) 15221531 .

[23] Y. Ying, J.H. Garrett, I.J. Oppenheim, L. Soibelman, J.B. Harley, J. Shi, Y. Jin, Toward Data-Driven Structural Health Monitoring: Application of Machine Learning and Signal Processing to Damage Detection, J. Comput. Civ. Eng. 27 (2013) 667-680. https://doi.org/10.1061/(ASCE)CP.1943-5487.0000258.

[24] M. Sanayei, E.S. Bell, C.N. Javdekar, J.L. Edelmann, E. Slavsky, Damage Localization and Finite-Element Model Updating Using Multiresponse NDT Data, J. Bridg. Eng. 11 (2006) 688-698. https://doi.org/10.1061/(ASCE)1084-0702(2006)11:6(688).

[25] C. Gentile, A. Saisi, Ambient vibration testing of historic masonry towers for structural identification and damage assessment, Constr. Build. Mater. 21 (2007) 1311-1321. https://doi.org/10.1016/j.conbuildmat.2006.01.007.

[26] I. Venanzi, A. Kita, N. Cavalagli, L. Ierimonti, F. Ubertini, Continuous OMA for damage detection and localization in the Sciri Tower in Perugia, Italy, in: 8th IOMAC - Int. Oper. Modal Anal. Conf. Proc., 2019: pp. 127-136.

[27] C. Gentile, M. Guidobaldi, A. Saisi, One-year dynamic monitoring of a historic tower: damage detection under changing environment, Meccanica. 51 (2016) 2873-2889. https://doi.org/10.1007/s11012-016-0482-3.

[28] J. Rodriguez, Identificação Modal Estocástica: Métodos de Análise e Aplicações em Estruturas de Engenharia Civil, 2004.

[29] A.P. Brincker R, Zhang L, Modal identification from ambient responses using frequency domain decomposition, in: Proc. 18th Int. Modal Anal. Conf. San Antonio, TX, Febr., San Antonio, Texas, 2000: pp. 625-630.

[30] B. Peeters, G. De Roeck, Reference-Based Stochastic Subspace Identification for Output-Only Modal Analysis, Mech. Syst. Signal Process. 13 (1999) 855-878. https://doi.org/10.1006/mssp.1999.1249.

[31] ARTeMIS Modal, (2018).

[32] Ministero delle Infrastrutture e dei Trasporti, D.M 17 gennaio 2018 "Aggiornamento delle Norme tecniche per le Costruzioni," Suppl. Ordin. Alla "Gazzetta Uff. n. 42 Del 20 Febbraio 2018- Ser. Gen. (2018) 1-198.

[33] R.S. Olivito, S. Porzio, A new multi-control-point pushover methodology for the seismic assessment of historic masonry buildings, J. Build. Eng. 26 (2019) 100926. https://doi.org/10.1016/j.jobe.2019.100926.

[34] S. Bagchi, T.B. Roy, A. Bagchi, Multiple damage localization of gravity dam: Strain energy based approach using random data, Proceedings, Annu. Conf. - Can. Soc. Civ. Eng. 2019-June (2019).

[35] Á. Bautista-De Castro, L.J. Sánchez-Aparicio, P. Carrasco-García, L.F. Ramos, D. González-Aguilera, A multidisciplinary approach to calibrating advanced numerical 
simulations of masonry arch bridges, Mech. Syst. Signal Process. 129 (2019) 337-365. https://doi.org/10.1016/j.ymssp.2019.04.043.

[36] A. Aloisio, I. Capanna, R. Cirella, R. Alaggio, F. Di Fabio, M. Fragiacomo, Identification and Model Update of the Dynamic Properties of the San Silvestro Belfry in L'Aquila and Estimation of Bell's Dynamic Actions, Appl. Sci. 10 (2020). https://doi.org/10.3390/app10124289.

[37] C. Leyder, E. Chatzi, A. Frangi, Vibration-based model updating of a timber frame $\begin{array}{lllll}\text { structure, } & \text { Procedia } & \text { Eng. } & 199 & \text { (2017) }\end{array}$ https://doi.org/10.1016/j.proeng.2017.09.141.

[38] T. Zordan, B. Briseghella, T. Liu, Finite element model updating of a tied-arch bridge using Douglas-Reid method and Rosenbrock optimization algorithm, J. Traffic Transp. Eng. (English Ed. 1 (2014) 280-292. https://doi.org/10.1016/S2095-7564(15)30273-7.

[39] J.P. Escallón, C. Wendeler, E. Chatzi, P. Bartelt, Parameter identification of rockfall protection barrier components through an inverse formulation, Eng. Struct. 77 (2014) 116. https://doi.org/10.1016/j.engstruct.2014.07.019.

[40] S. Kokot, Z. Zembaty, Damage reconstruction of 3D frames using genetic algorithms with Levenberg--Marquardt local search, Soil Dyn. Earthq. Eng. 29 (2009) 311-323. https://doi.org/10.1016/j.soildyn.2008.03.001. 